\section{Perinatal Mortality}

The first report of the 1958 British Perinatal Mortality Survey. N. R. BUTLER and D. G. BonHam. Pp. 304. Edinburgh \& London: E. \& S. Livingstone. 1963. 30s.

This century has seen a greater fall in the mortality of children in this country than any other century, indeed than perhaps all others put together. This fall in mortality, however, has been inversely related to the age of the child. As a result, the efforts of pædiatric research, and of the practical measures that flow from it, have been directed mainly to the younger child; to the infant mortality, or deaths in the first year, the neonatal mortality, the deaths in the first month, and finally the perinatal mortality. This is the latest and possibly the last sophistication, the combination of stillbirths with deaths in the first week of life.

This zone of infant mortality is the least susceptible of all to improvement, bringing in as it does important genetic, obstetric, and sociological considerations. In 1953, The National Birthday Trust Fund decided that a thorough survey was needed, on a national scale, to establish once and for all, the ætiological factors behind this mortality. This vast undertaking could not begin until 1958, and has now produced its first fruit in this report. For this purpose, information was collected for all births in the country during one week in 1958, and for all stillbirths and neonatal deaths for the following three months. The basis of the enquiry was a truly formidable questionaire for each baby, in spite of which it is calculated that a $98 \%$ response was obtained for births, and $94 \%$ for deaths - a superb result.

The analysis covers all conceivable influences on mortality, geographical, sociological, obstetric, and pathological, and a large number of distinguished collaborators in many fields were brought in. The report is presented basically as a series of tables and diagrams, with very useful explanatory summaries alongside. It could not be claimed that this makes light reading, but it is certainly a good deal more readable than many similar statistical digests. Henceforward, nobody can plead ignorance about the causes of perinatal mortality. Dr. Butler and Professor Bonham are to be congratulated on this unique achievement, which will be the standard work of reference for years to come. Subsequent reports will be eagerly awaited.

\section{Biochemical Problems of Lipids}

Edited by A. C. Frazer. Pp. ix +474 , illustrated. Amsterdam, London and New York: Elsevier. 1963. 130s.

Sixty papers were presented at the 7 th International Conference on biochemical problems of lipids in July 1962, at Birmingham, England. This volume contains a full text of 54 of them and abstracts of two others. There was a year's delay in publication which is rather long for a field moving forwards as rapidly as this one. Nevertheless, the production of a book such as this represents a considerable achievement. The central theme of the conference was the absorption of lipids from the gastrointestinal tract and this field is very thoroughly explored in all its aspects. The scope of the book is however wider than the limitations this title might suggest. The first two papers present very valuable data on thin layer chromatography of lipids while the sixth and last section of the book is devoted to wider aspects of lipid metabolism ranging as far afield for example as "On the ability of the cholesterol esters of the aorta wall to be identical with those of the serum". The standard of production is high and some of the papers are lavishly illustrated both with diagrams and full page photographs. Most of the papers are in English; a few are in French but these have English summaries. A subject and author index, items frequently overlooked in works such as this, are provided and help to make this a valuable work of reference for research workers in the field of lipid metabolism.

\section{Psychiatry for Students}

David Stafford-Clark. Pp. 277. London: George Allen and Unwin, 1964. 35s.

The author addresses his book to wide audiences which may be "medical, dental, sociological, psychological or philosophical; undergraduate or postgraduate." Perhaps it is because his aim is to interest and instruct persons from so many disciplines that he gives only brief clinical descriptions of the various psychiatric syndromes. Here is the main disadvantage of this book for the undergraduate or postgraduate student of medicine. However, read with a text giving more detailed clinical accounts, this book is sure to stimulate those embarking on their psychiatric studies and the reviewer will have no hesitation in recommending it as an introduction to psychiatry.

The chapter on "Child Psychiatry" by Dr. Gerard Vaughan, although reduplicating at times information earlier presented in the chapter on "Personality Development", is a most useful and balanced account of this subject. The life charts displayed in Chapter 12 clearly demonstrate how, with advantage, more general use could be made of this method in order to tabulate clinical information. On the section on treatment, hypnosis is considered in detail and an appendix is devoted to experts from recordings made during the induction of hypnosis. It is to be hoped that clinicians who continue to use intramuscular paraldehyde as a form of sedation will note the author's objections to this measure and dismiss it from their therapeutic armamentarium.

The student who wishes to read beyond an introductory text is liable, without guidance, to do so indiscriminately and is in danger of equating all schools of thought as having equal significance. Accordingly, the author has listed a number of books valuable in teaching both undergraduates and postgraduates, and few psychiatrists would disagree with this representative selection.

\section{Programmed Genetics Volume 1: The Basic Concepts}

Edited by Chester A. Lawson and Mary Alice Burmester. Pp. 330. Boston: D. C. Heath and Company. 1963. 38s. 5d.

The word "programmed" of the title refers to the method of presentation of information to the reader. The material is divided into a series of small units which are "scrambled", i.e. do not appear on con- 